\title{
The Prognostic Impact of Preoperative Serum Apolipoprotein A-I in Patients with Esophageal Basaloid Squamous Cell Carcinoma
}

\author{
Ji-Feng Feng' \\ Jian-Ming Zhao ${ }^{2}$ \\ Xun Yang ${ }^{\prime}$ \\ Liang Wang'
}

'Department of Thoracic Oncological Surgery, Institute of Cancer Research and Basic Medical Sciences of Chinese Academy of Sciences, Cancer Hospital of University of Chinese Academy of Sciences, Zhejiang Cancer Hospital, Hangzhou, Zhejiang Province, People's Republic of China; ${ }^{2}$ Department of Thoracic Surgery, Jinhua Guangfu Hospital, Jinghua, Zhejiang Province, People's Republic of China
Correspondence: Ji-Feng Feng; Liang

Wang

Email fengif@I63.com; drwang_ liang@126.com
Background: Esophageal basaloid squamous cell carcinoma (EBSCC) is a rare malignancy. Serum apolipoprotein A-I (APO A-I) has proved to be a potentially useful prognostic indicator in various cancers. However, no studies have analyzed the prognostic significance of serum APO A-I in patients with EBSCC. The aim of this study was to investigate the prognostic impact of preoperative serum APO A-I in patients with EBSCC.

Methods: Between 2007 and 2018, a retrospective study of 4050 patients with resectable esophageal squamous cell carcinoma (ESCC) including the levels of preoperative serum lipids was conducted and evaluated. The best cut-off values of the preoperative serum lipids were evaluated by receiver operating characteristic (ROC) curves. Kaplan-Meier analyses and Cox regression analyses were analyzed the overall survival (OS) and recurrence-free survival (RFS). A prediction model of nomogram was developed to predict individual OS and RFS in EBSCC.

Results: There were 53 patients enrolled in the study, which accounted for $1.31 \%(53 / 4050)$ of all primary ESCC. The best cut-off point was $1.305 \mathrm{~g} / \mathrm{L}$ for serum APO A-I according to the ROC curve. Patients with lower levels of serum preoperative APO A-I were associated with worse RFS $(16.1 \%$ vs $54.5 \%, P=0.006)$ and OS $(29.0 \%$ vs $63.6 \%, P=0.010)$. The results indicated that serum APO A-I serves as an independent predictor in patients with EBSCC regarding OS [hazard ratio (HR): 0.352 ; 95\% confidence interval (CI): 0.154-0.808; $P=0.014]$ and RFS (HR: 0.397; 95\% CI: $0.185-0.850 ; P=0.017$ ).

Conclusion: Preoperative serum APO A-I is an independent predictor regarding OS and RFS in EBSCC. As far as we know, this is the first study in EBSCC to explore the serum APO A-I in patients with EBSCC.

Keywords: esophageal basaloid squamous cell carcinoma, EBSCC, apolipoprotein A-I, APO A-I, recurrence-free survival, RFS, overall survival, OS, prognosis

\section{Introduction}

As a specific subtype of squamous cell carcinoma (SCC), basaloid squamous cell carcinoma (BSCC) was first reported in head and neck by Wain et al in $1986 .{ }^{1}$ Esophageal basaloid squamous cell carcinoma (EBSCC) is a rare malignancy. Due to the rarity of EBSCC, it is difficult to establish the standard treatment. There are only a few case reports and small samples reports have been revealed in the literature. $^{2-4}$ Surgical resection is the best choice for EBSCC patients with localized lesions according to the published studies, however, the prognosis remains

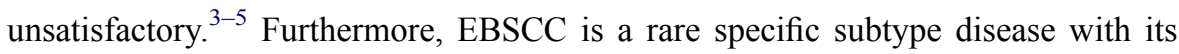


own molecular features and biological behaviors, the prognostic biomarkers in patients with EBSCC remain controversial. $^{5,6}$

Abnormal lipid metabolism has been reported to play a critical role in cancer progression and prognosis. ${ }^{7,8}$ Apolipoprotein A-I (APO A-I), as the main protein constituent of high-density lipoprotein-cholesterol (HDL-C), is involved in the regulation of lipid metabolism. ${ }^{9,10}$ In addition, several studies have reported that APO A-I has anti-oxidant, anti-inflammatory, anti-apoptotic, and other atherosclerotic protective functions. ${ }^{11,12}$ Therefore, it is intuitively possible to hypothesize that APO A-I may also have a protective effect against cancer. Recent studies reported that serum APO A-I is a useful predictor in predicting prognosis in a variety of cancers, ${ }^{13-16}$ including ESCC. ${ }^{17}$ Furthermore, a meta-analysis including 14 studies of 9295 patients and another meta-analysis including 13 studies of 8052 patients revealed that high levels of serum APO A-I were significantly associated with better overall survival (OS). ${ }^{16,18}$

EBSCC is a rare specific subtype disease with its own molecular features and biological behavior, ${ }^{5,6}$ and its differentiation and prognosis are worse than those of ESCC. ${ }^{17}$ Recent studies reported that serum levels of APO A-I were significantly lower in ESCC patients than those in normal controls, and patients with lower levels of APO A-I had poor survival. ${ }^{17}$ To the best of our knowledge, there are no study regarding the associations between serum APO A-I and EBSCC so far. The aim of this study, therefore, was to explore the prognostic impact of preoperative serum APO A-I regarding recurrence-free survival (RFS) and OS in patients with EBSCC. A prediction model of nomogram based on serum APO A-I was also developed to predict individual OS and RFS in EBSCC.

\section{Patients and Methods}

\section{Ethics Statement}

The present study was conducted in accordance with the Declaration of Helsinki and approved by the ethics committee of Zhejiang Cancer Hospital (2020-031). The requirement of patients' consent was waived because of its retrospective feature and anonymous data.

\section{Patients}

From 2007 to 2018, patients with EBSCC who underwent curative esophagectomy were included in this retrospective study. The inclusion criteria were as follows: (1) resectable EBSCC (TNM stage I-III) was confirmed by histopathology, (2) radical resection was conducted without any neoadjuvant treatment, (3) patients were included without any other tumors or distant metastases, and (4) preoperative serum lipids, including triglyceride (TG), total cholesterol (TC), apolipoprotein B (APO B), lowdensity lipoprotein-cholesterol (LDL-C), HDL-C and APO A-I, were obtained one week before surgery. The exclusion criteria were as follows: (1) patients diagnosed in other pathological types, (2) without radical resection or with distant metastases, (3) treated with neoadjuvant treatments before surgery, (4) malignant tumors in previous or synchronous, (5) incomplete clinical data or preoperative laboratory results, or (6) without detailed follow-up data.

\section{Treatment and Follow-Up}

The standard surgical resection was performed in the current study including two procedures (Ivor Lewis for EBSCC patients in the middle or lower third and McKeown for EBSCC patients in the upper third) with two-field lymphadenectomy. ${ }^{19,20}$ The clinical characteristic data of EBSCC patients were obtained retrospectively from our medical records and evaluated these data as prognostic factors. The clinical characteristics included age, gender, drinking and smoking histories, tumor length, TNM stage, tumor location, vessel invasion and laboratory results including preoperative serum TG, TC, HDL-C, LDL-C, APO B and APO A-I. The TNM stage in this study was conducted according to the 8th AJCC/UICC TNM staging system. ${ }^{21}$ Smoking and drinking habits regarding in the current study were defined as a history of smoking and drinking in the past, whether or not the patient was currently abstained. The follow-up results were obtained from our hospital records. Patients were checked every three months during the first two years, every six months for the next three years, and once a year thereafter. The last follow-up for the current study was completed in March 2019.

\section{Statistical Analyses}

The best cut-off values of the serum lipids (TG, HDL-C, LDL-C, APO B, APO A-I and TC) were evaluated by the receiver operating characteristic (ROC) curves according to the OS. The chi-squared test and $t$-test were utilized to analyze the clinical data of EBSCC grouped by serum APO A-I. The OS and RFS were evaluated with Cox regression analyses. Variables with statistical differences in univariate analyses combined with baseline factors including 
age and gender were then subjected to multivariate analyses by using a forward stepwise. Two prognostic nomograms regarding RFS and OS were established based on the multivariate analyses results by using Cox proportional hazard model with R 3.6.0 software. ${ }^{22}$ Calibration curves of survival prediction for the nomogram were performed. Decision curves and time-dependent ROC curves were also used to evaluate the discriminative ability and predictive accuracy, and compared with the traditional TNM staging system. Statistical analyses were performed with SPSS 20.0 (SPSS Inc., Chicago, IL, USA) and MedCalc 17.6 (MedCalc Software, Ostend, Belgium). P-values less than 0.05 were considered to be statistically significant.

\section{Results}

\section{Baseline Characteristics}

From 2007 to 2018, a total of 4050 ESCC patients who underwent surgical resection were analyzed. There were only 53 patients with EBSCC in this study, which accounted for $1.31 \%$ (53/4050) of all ESCC. A mean follow-up time for all 53 EBSCC patients was 40 months (range: 5-138 months). Pathological results indicated that the tumor cells were arranged in nests, lobules or trabecular basaloid cells. Nuclear palisading was arranged in the peripheral region of tumor nests with hyaline-like materials identified. Immunohistochemical results revealed that the tumor cells were positive for P63 and P40 (Figure 1).

\section{Correlations Between APO A-I and Other Serum Lipids}

The histograms of the serum LDL-C, HDL-C, APO B, APO A-I, TG and TC were shown in Figure 2A-F. The mean value of APO A-I was $1.26 \pm 0.24 \mathrm{~g} / \mathrm{L}$. The heatmap of correlations between serum APO A-I and other serum lipids were shown in Figure 2G. Positive correlations were found between serum HDL-C and APO A-I (r=0.798, $P<0.001)$, TC and TG ( $\mathrm{r}=0.495, P<0.001)$, TG and LDL-C ( $\mathrm{r}=0.392$, $P=0.001)$, TG and APO B ( $\mathrm{r}=0.430, P=0.001)$, TC and LDL$\mathrm{C}(\mathrm{r}=0.877, P<0.001), \mathrm{TC}$ and APO B $(\mathrm{r}=0.855, P<0.001)$, LDL-C and APO B (r=0.910, $P<0.001)$, respectively.

\section{Characteristics Grouped by APO A-I}

The best cut-off points for serum LDL-C, HDL-C, APO B, APO A-I, TG and TC according to the ROC curves were $3.305 \mathrm{mmol} / \mathrm{L}, 1.220 \mathrm{mmol} / \mathrm{L}, 1.010 \mathrm{~g} / \mathrm{L}, 1.305 \mathrm{~g} / \mathrm{L}, 1.325$ $\mathrm{mmol} / \mathrm{L}$ and $4.400 \mathrm{mmol} / \mathrm{L}$, respectively (Figure 3 ). Based on the cut-off value of serum APO A-I $(1.305 \mathrm{~g} / \mathrm{L})$, patients were divided into two groups (high and low

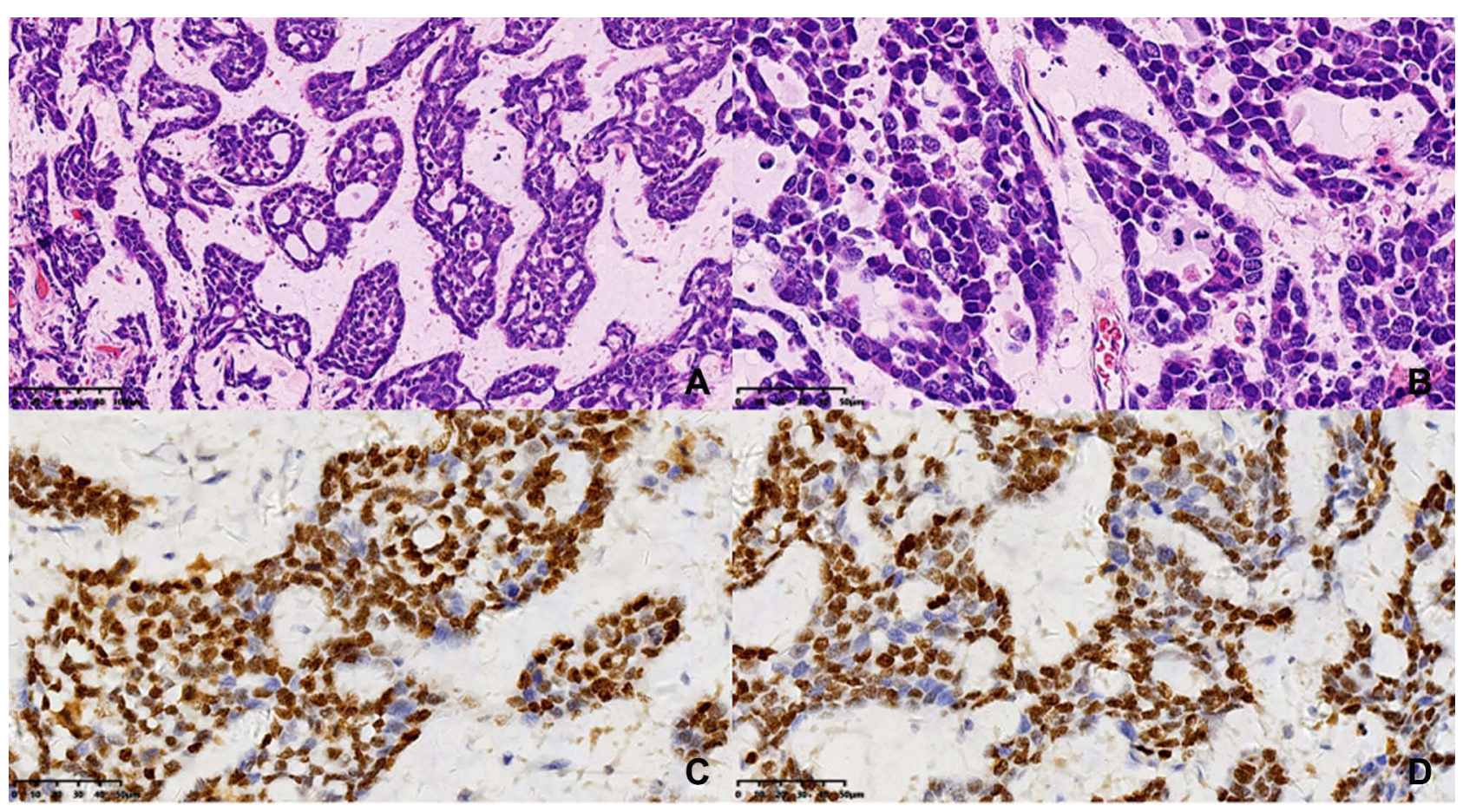

Figure I Pathological and immunohistochemical results. Tumor cells were arranged in nests, lobules or trabecular basaloid cells. Nuclear palisading was arranged in the

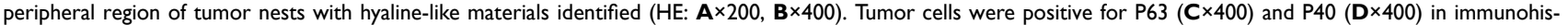
tochemical results. 

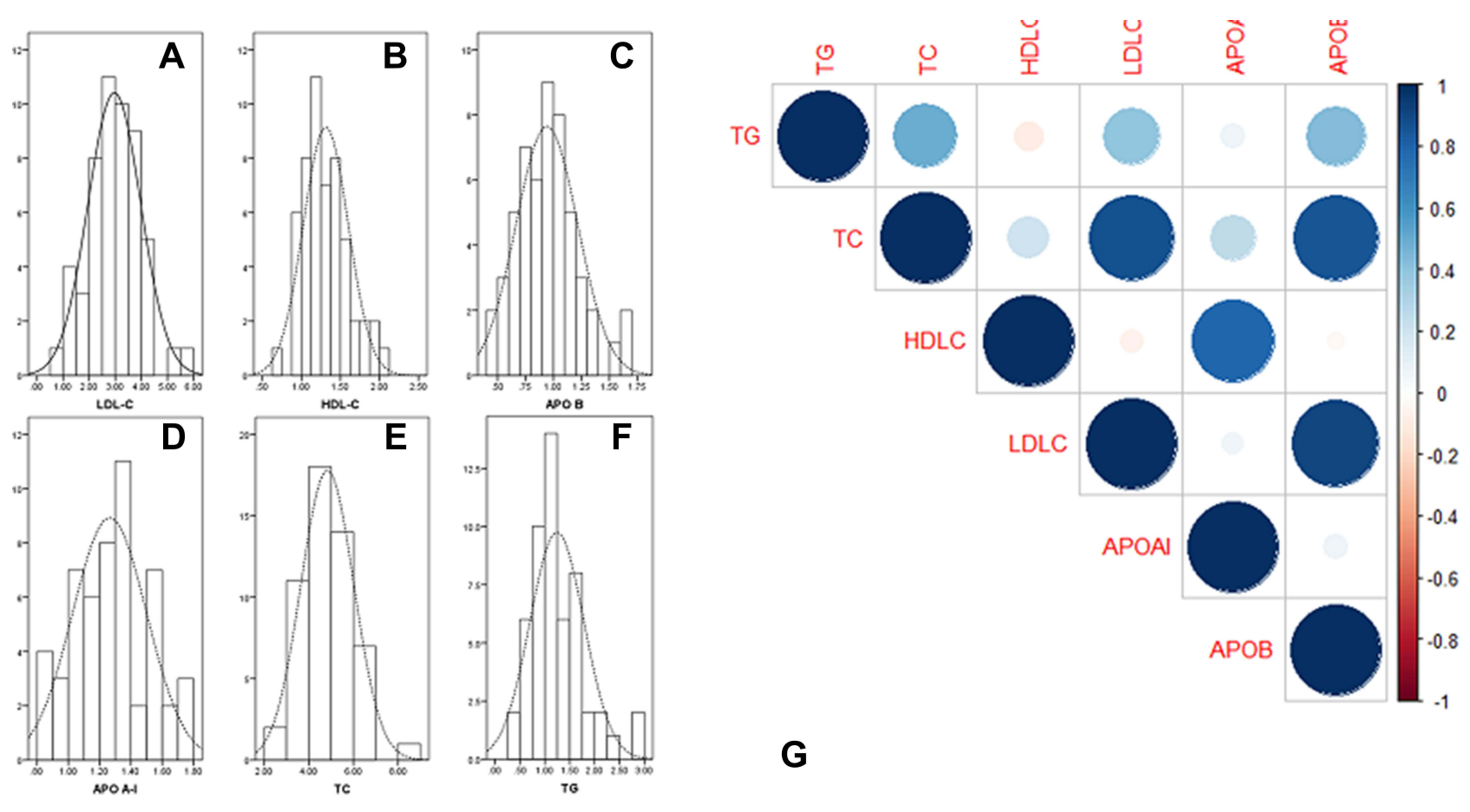

Figure 2 The histograms $(\mathbf{A}-\mathbf{F})$ and heatmap $(\mathbf{G})$ of the serum lipids. According to the heatmap, positive correlations were found between $\mathrm{HDL}-\mathrm{C}$ and $\mathrm{APO} A-\mathrm{I}$ ( $\mathrm{r}=0.798$, $P<0.00 \mathrm{I})$, TC and TG $(r=0.495, P<0.00 \mathrm{I})$, TG and LDL-C $(r=0.392, P=0.00 \mathrm{I})$, TG and APO B $(r=0.430, P=0.00 \mathrm{I})$, TC and LDL-C $(r=0.877, P<0.00 \mathrm{I}), \mathrm{TC}$ and APO $B(r=0.855, P<0.001)$, LDL-C and APO B $(r=0.910, P<0.001)$, respectively.
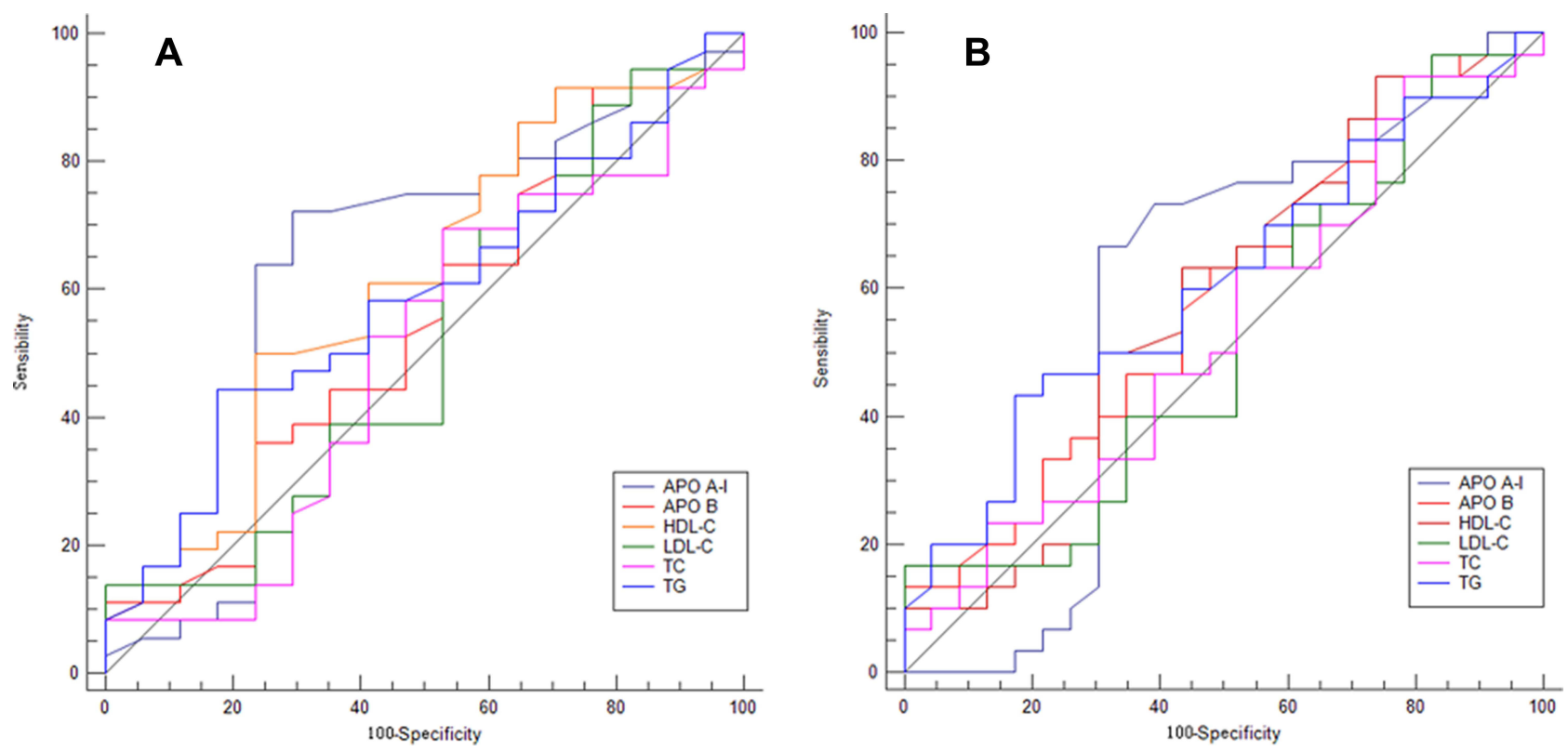

Figure 3 ROC curves analyses. ROC curves for serum LDL-C, HDL-C, APO B, APO A-I, TG and TC regarding RFS (A) and OS (B) regarding the best cut-off points.

group) for further analyses. Serum preoperative APO A-I was significantly associated with drinking history $(P=0.033)$, tumor length $(P=0.025)$ and serum HDL-C $(P<0.001)$ (Table 1). Although the levels of APO A-I were higher in patients with no drinking history than those with drinking history, no differences were found regarding the levels of APO A-I grouped by drinking history $(1.32 \pm 0.22 \mathrm{~g} / \mathrm{L}$ versus $1.23 \pm 0.24 \mathrm{~g} / \mathrm{L}, P=0.571)$.

\section{RFS, OS and Cox Regression Analyses}

Patients with lower levels of preoperative serum APO A-I were associated with worse RFS $(16.1 \%$ vs $54.5 \%$, 
Table I Comparison of Baseline Clinical Characteristics Based on APO a-I in EBSCC

\begin{tabular}{|c|c|c|c|c|}
\hline & Cases (n, \%) & Low Group $(n=31)$ & High Group (n=23) & P-value \\
\hline Age (years) & & & & 0.076 \\
\hline$\leq 60$ & $22(41.5)$ & $16(51.6)$ & $6(27.3)$ & \\
\hline$>60$ & $31(58.5)$ & $15(48.4)$ & $16(72.7)$ & \\
\hline Gender & & & & 0.094 \\
\hline Female & II (20.8) & $4(12.9)$ & $7(31.8)$ & \\
\hline Male & $42(79.2)$ & $27(87.1)$ & $15(68.2)$ & \\
\hline Tumor length $(\mathrm{cm})$ & $3.93 \pm 1.67$ & $4.36 \pm 1.75$ & $3.33 \pm 1.37$ & 0.025 \\
\hline$\leq 3.0$ & $16(30.2)$ & $7(22.6)$ & $9(40.9)$ & 0.152 \\
\hline$>3.0$ & $37(69.8)$ & $24(77.4)$ & $13(59.1)$ & \\
\hline Tumor location & & & & 0.079 \\
\hline Upper/Middle & $36(67.9)$ & $24(77.4)$ & $12(54.5)$ & \\
\hline Lower & $17(32.1)$ & $7(22.6)$ & $10(45.5)$ & \\
\hline Vessel invasion & & & & 0.973 \\
\hline Negative & $36(67.9)$ & $21(67.7)$ & $15(68.2)$ & \\
\hline Positive & $17(32.1)$ & $10(32.3)$ & $7(31.8)$ & \\
\hline Smoking history & & & & 0.329 \\
\hline No & $20(37.7)$ & $10(32.3)$ & $10(45.5)$ & \\
\hline Yes & $33(62.3)$ & $21(67.7)$ & $12(54.5)$ & \\
\hline Drinking history & & & & 0.033 \\
\hline No & $20(37.7)$ & $8(25.8)$ & $12(54.5)$ & \\
\hline Yes & $33(62.3)$ & $23(74.2)$ & $10(45.5)$ & \\
\hline TNM stage & & & & 0.728 \\
\hline I & $25(47.2)$ & $14(45.2)$ & II (50.0) & \\
\hline II-III & $28(52.8)$ & $17(54.8)$ & II (50.0) & \\
\hline Surgery treatment & & & & 0.781 \\
\hline Ivor Lewis & $35(66.0)$ & $20(64.5)$ & $15(68.2)$ & \\
\hline McKeown & $18(34.0)$ & II (25.5) & $7(31.8)$ & \\
\hline Adjuvant treatment & & & & 0.075 \\
\hline No & $39(73.6)$ & $20(64.5)$ & $19(86.4)$ & \\
\hline Yes & $14(26.4)$ & II (35.5) & $3(13.6)$ & \\
\hline $\mathrm{TC}(\mathrm{mmol} / \mathrm{L})$ & $4.83 \pm 1.19$ & $4.67 \pm 1.10$ & $5.06 \pm 1.30$ & 0.238 \\
\hline$\leq 4.400$ & $18(34.0)$ & $12(38.7)$ & $6(27.3)$ & 0.386 \\
\hline$>4.400$ & $35(66.0)$ & $19(61.3)$ & $16(72.7)$ & \\
\hline TG (mmol/L) & $1.24 \pm 0.54$ & $1.25 \pm 0.6 \mathrm{I}$ & $1.23 \pm 0.45$ & 0.920 \\
\hline$\leq 1.325$ & $33(62.3)$ & $19(61.3)$ & $14(63.6)$ & 0.862 \\
\hline$>1.325$ & $20(37.7)$ & $12(38.7)$ & $8(36.4)$ & \\
\hline $\mathrm{HDL}-\mathrm{C}(\mathrm{mmol} / \mathrm{L})$ & $1.31 \pm 0.29$ & $1.15 \pm 0.19$ & $1.54 \pm 0.26$ & $<0.001$ \\
\hline$\leq 1.220$ & $29(54.7)$ & $26(83.9)$ & $3(13.6)$ & $<0.001$ \\
\hline$>1.220$ & $24(45.3)$ & $5(16.1)$ & $19(86.4)$ & \\
\hline LDL-C (mmol/L) & $2.97 \pm 1.02$ & $2.93 \pm 0.93$ & $3.01 \pm 1.14$ & 0.777 \\
\hline$\leq 3.305$ & $35(66.0)$ & $23(74.2)$ & $12(54.5)$ & 0.137 \\
\hline$>3.305$ & $18(34.0)$ & $8(25.8)$ & $10(45.5)$ & \\
\hline APO B $(g / L)$ & $0.94 \pm 0.28$ & $0.93 \pm 0.29$ & $0.95 \pm 0.27$ & 0.792 \\
\hline$\leq 1.010$ & $32(60.4)$ & $19(61.3)$ & $13(59.1)$ & 0.872 \\
\hline$>1.010$ & $21(39.6)$ & $12(38.7)$ & $9(40.9)$ & \\
\hline
\end{tabular}


Table I (Continued).

\begin{tabular}{|c|l|l|l|l|}
\hline & Cases (n, \%) & Low Group $(\mathbf{n}=\mathbf{3}$ I) & High Group $(\mathbf{n}=23)$ & P-value \\
\hline BMI $\left(\mathrm{kg} / \mathrm{m}^{2}\right)$ & $22.1 \pm 2.1$ & $22.5 \pm 2.4$ & $21.6 \pm 1.5$ & 0.113 \\
$\leq 22.5$ & $31(58.5)$ & $15(48.4)$ & $16(72.7)$ & 0.076 \\
$>22.5$ & $22(41.5)$ & $16(51.6)$ & $6(27.3)$ & \\
\hline
\end{tabular}

Note: $P$-values $<0.05$ were shown in bold.

Abbreviations: EBSCC, esophageal basaloid squamous cell carcinoma; TC, total cholesterol; TG, triglyceride; Apo A-I, apolipoprotein A-I; Apo B, apolipoprotein B; HDLC, high-density lipoprotein-cholesterol; LDL-C, low-density lipoprotein-cholesterol; TNM, tumor, node, metastasis.

$P=0.006)$ and $\mathrm{OS}(29.0 \%$ vs $63.6 \%, P=0.010)$ (Figure 4$)$. In univariate analyses, RFS was significantly associated with tumor length $(P=0.006)$, APO A-I $(P=0.009)$ and TNM stage $(P=0.004)$ while OS was significantly associated with TNM stage $(P=0.010)$, tumor length $(P=0.028)$, APO A-I $(P=0.014)$ and serum TG $(P=0.033)$. Subsequently, prognostic factors significantly associated with OS or RFS in univariate analysis and baseline factors such as age and results revealed that serum APO A-I was an independent indicator regarding OS [Hazard ratio (HR): 0.352; 95\% confidence interval $(\mathrm{CI}): 0.154-0.808 ; P=0.014)]$ and RFS (HR: $0.397 ; 95 \%$ CI: $0.185-0.850 ; P=0.017$ ) in multivariate analyses (Tables 2 and 3).

\section{Nomogram Analyses}

Nomograms were used to predict the OS or RFS probability for patients with EBSCC by using independent prognostic factors (TNM, TG and APO A-I for OS) and (TNM, tumor length and APO A-I for RFS) in multivariate analyses (Figure 5). The survival probability of EBSCC patients (1-, 3- and 5-year OS or RFS) could be predicted according to

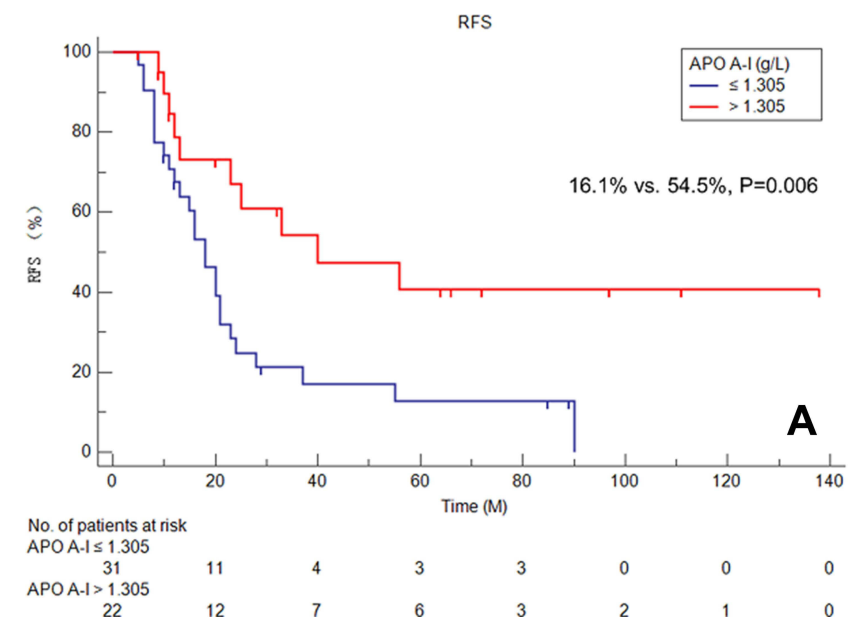
gender were combined into multivariate Cox analysis. The

this model (c-index $=0.74$ for OS and $c$-index $=0.69$ for RFS) (Figure 6). The calibration curve presented an acceptable agreement regarding the individual OS and RFS prediction. Time-dependent ROC curve analyses revealed that the prediction of nomogram was significant higher than traditional TNM staging systems. The APO A-I-based nomogram model had higher overall net benefits than traditional TNM staging systems according to the decision curve analyses.

\section{Discussion}

To our knowledge, this is the first study in EBSCC patients to investigate the prognostic role of preoperative serum APO A-I. In this retrospective study, we found that patients with lower levels of preoperative serum APO A-I were associated with worse RFS (16.1\% vs 54.5\%, $P=0.006)$ and OS $(29.0 \%$ vs $63.6 \%, P=0.010)$. Moreover, we firstly performed a nomogram by using TNM, TG and serum APO A-I to predict the OS probability in patients with EBSCC. According to this model, we can assess the prognosis (1-, 3- and 5-year OS or RFS) of each patient with EBSCC.

The histopathological characteristics between EBSCC and ESCC were different. The incidence of EBSCC ranges
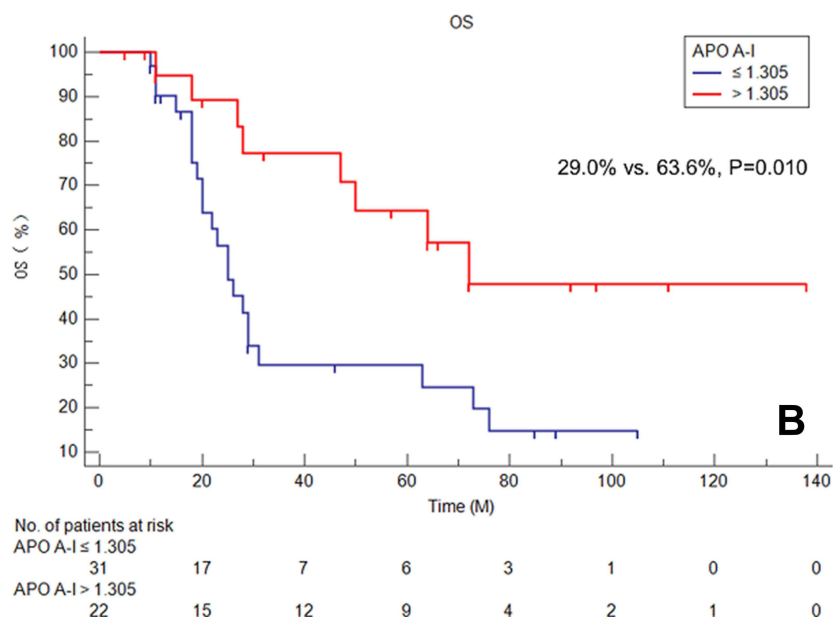

Figure 4 RFS and OS analyses. Patients with lower levels of serum APO A-I were associated with worse RFS (16.1\% vs $54.5 \%, P=0.006 ;(\mathbf{A})$ and OS $(29.0 \%$ vs $63.6 \%$, $P=0.010$; (B). 
Table 2 Univariate and Multivariate Analyses of RFS in EBSCC Patients

\begin{tabular}{|c|c|c|c|c|}
\hline & \multirow{2}{*}{$\begin{array}{c}\text { Univariate Analyses } \\
\text { HR }(95 \% \mathrm{Cl})\end{array}$} & \multirow[t]{2}{*}{ P-value } & \multirow{2}{*}{$\begin{array}{c}\text { Multivariate Analyses } \\
\text { HR }(95 \% \mathrm{Cl})\end{array}$} & \multirow[t]{2}{*}{ P-value } \\
\hline & & & & \\
\hline Age (years) & & 0.392 & & \\
\hline$\leq 60$ & 1.000 & & & \\
\hline$>60$ & $0.748(0.386-1.453)$ & & & \\
\hline Gender & & 0.382 & & \\
\hline Female & 1.000 & & & \\
\hline Male & $1.450(0.63|-3.33|)$ & & & \\
\hline Tumor length $(\mathrm{cm})$ & & 0.006 & & 0.048 \\
\hline$\leq 3.0$ & 1.000 & & 1.000 & \\
\hline$>3.0$ & $3.428(1.4 \mid 2-8.323)$ & & $2.494(1.010-6.160)$ & \\
\hline Tumor location & & 0.582 & & \\
\hline Upper/Middle & 1.000 & & & \\
\hline Lower & $0.8 I 9(0.40 I-\mid .67 I)$ & & & \\
\hline Vessel invasion & & 0.358 & & \\
\hline Negative & 1.000 & & & \\
\hline Positive & $1.397(0.685-2.850)$ & & & \\
\hline Smoking history & & 0.093 & & \\
\hline No & 1.000 & & & \\
\hline Yes & $1.821(0.905-3.664)$ & & & \\
\hline Drinking history & & 0.176 & & \\
\hline No & 1.000 & & & \\
\hline Yes & $1.619(0.806-3.251)$ & & & \\
\hline TNM stage & & 0.004 & & 0.009 \\
\hline 1 & 1.000 & & 1.000 & \\
\hline II-III & $2.784(1.378-5.627)$ & & $2.673(1.283-5.568)$ & \\
\hline Surgery treatment & & 0.772 & & \\
\hline McKeown & 1.000 & & & \\
\hline Ivor Lewis & $0.460(0.388-1.534)$ & & & \\
\hline Adjuvant treatment & & 0.695 & & \\
\hline No & 1.000 & & & \\
\hline Yes & I.I $49(0.573-2.302)$ & & & \\
\hline $\mathrm{TC}(\mathrm{mmol} / \mathrm{L})$ & & 0.443 & & \\
\hline$\leq 4.400$ & 1.000 & & & \\
\hline$>4.400$ & $1.324(0.646-2.712)$ & & & \\
\hline $\mathrm{TG}(\mathrm{mmol} / \mathrm{L})$ & & 0.097 & & \\
\hline$\leq 1.325$ & 1.000 & & & \\
\hline$>1.325$ & $1.745(0.904-3.368)$ & & & \\
\hline HDL-C (mmol/L) & & 0.201 & & \\
\hline$\leq 1.220$ & 1.000 & & & \\
\hline$>1.220$ & $0.644(0.328-1.264)$ & & & \\
\hline LDL-C (mmol/L) & & 0.885 & & \\
\hline$\leq 3.305$ & 1.000 & & & \\
\hline$>3.305$ & $0.949(0.466-1.934)$ & & & \\
\hline
\end{tabular}

(Continued) 
Table 2 (Continued).

\begin{tabular}{|c|c|c|c|c|}
\hline & Univariate Analyses & P-value & Multivariate Analyses & P-value \\
\hline & HR $(95 \% \mathrm{Cl})$ & & HR $(95 \% \mathrm{Cl})$ & \\
\hline $\begin{array}{l}\text { APO A-I }(\mathrm{g} / \mathrm{L}) \\
\quad \leq 1.305 \\
>1.305\end{array}$ & $\begin{array}{l}1.000 \\
0.373(0.177-0.784)\end{array}$ & 0.009 & $\begin{array}{l}1.000 \\
0.397(0.185-0.850)\end{array}$ & 0.017 \\
\hline $\begin{array}{l}\text { APO B }(\mathrm{g} / \mathrm{L}) \\
\quad \leq 1.010 \\
>1.010\end{array}$ & $\begin{array}{l}1.000 \\
0.716(0.360-1.423)\end{array}$ & 0.340 & & \\
\hline $\begin{array}{l}\text { BMI }\left(\mathrm{kg} / \mathrm{m}^{2}\right) \\
\quad \leq 22.5 \\
>22.5\end{array}$ & $\begin{array}{l}1.000 \\
0.873(0.447-1.704)\end{array}$ & 0.690 & & \\
\hline
\end{tabular}

Note: P-values $<0.05$ were shown in bold.

Abbreviations: EBSCC, esophageal basaloid squamous cell carcinoma; TC, total cholesterol; TG, triglyceride; Apo A-I, apolipoprotein A-I; Apo B, apolipoprotein B; HDL$\mathrm{C}$, high-density lipoprotein-cholesterol; LDL-C, low-density lipoprotein-cholesterol; TNM, tumor, node, metastasis; Cl, confidence interval; HR, hazard ratio; RFS, recurrence-free survival.

from $0.4 \%-5.3 \% .^{2-5,17,24,25}$ A study from SEER database compared the clinical treatment and survival characteristics between EBSCC and ESCC. The result revealed the incidence was $1.1 \%(173 / 16,158) .{ }^{23}$ In current study, the incidence of EBSCC was $1.31 \%$ (53/4050). Because of the rarity of EBSCC and the absence of clinical trials on the therapeutic strategy specific to EBSCC, no standard treatment for EBSCC has been established. Surgical resection is the best treatment for patients with EBSCC, however, the prognosis remains poor. The survival difference between EBSCC and ESCC remains controversial. Lam et $\mathrm{al}^{2}$ reported that no significant differences regarding the prognosis were found between patients with EBSCC and ESCC. But Chen et $\mathrm{al}^{26}$ and Imamhasan et $\mathrm{al}^{27}$ revealed that the median survival time (MST) and OS in patients with EBSCC were significantly worse than those with well differentiated ESCC, and similar to those of ESCC with poor and/or moderate differentiation.

Abnormal lipid metabolism has been reported to play a main role in progression and prognosis in a variety of cancers. ${ }^{7,8,28}$ Currently, serum APO A-I, as a serum index of nutritional and inflammatory status, became the research focus. The preoperative serum APO A-I serves as a useful prognostic factor in several cancers. ${ }^{13-17}$ In patients with ESCC, Wang et $\mathrm{al}^{17}$ reported the first study regarding serum APO A-I in patients with ESCC. They concluded that patients with low levels of pretreatment serum APO A-I were significantly associated with worse OS in ESCC. EBSCC is a rare specific subtype disease with its own molecular features and biological behavior. ${ }^{5,6}$
Furthermore, no study regarding the prognostic role of serum APO A-I so far has been assessed in EBSCC patients. Therefore, we conducted this retrospective study to explore the prognostic impact of preoperative serum APO A-I in EBSCC patients. In the current study, we divided these 53 EBSCC patients into two groups (high and low) based on the ROC curve. In our results, patients with lower level of serum APO A-I were associated with worse RFS (16.1\% vs 54.5\%, $P=0.006)$ and OS $(29.0 \%$ vs $63.6 \%, \mathrm{P}=0.010)$. Therefore, we concluded that serum APO A-I serves as an independent predictor of RFS $(P=0.017)$ and $\mathrm{OS}(P=0.014)$ in EBSCC patients in multivariate analyses.

The mechanism regarding APO A-I and cancer is still unknown. However, there are several potential explanations. Angiogenesis plays an important role in the progress and metastasis of cancers. ${ }^{29}$ Recent published studies reported that in mouse models of ovarian cancer, APO A-I mimetic peptides reduced tumor angiogenesis and suppressed tumor progress. ${ }^{30,31}$ Another plausible mechanism is that APO A-I can inhibit lysophosphatidic acid-induced cell growth, which is a well-known activator of proliferation in several cancers. ${ }^{10}$ A study published in recent years reported that APO A-I potently reduced tumor metastasis and suppressed tumor invasion in multiple animal tumor models. ${ }^{32}$ Another study revealed that APO A-I may exert an indirect antitumor effects by altering the macrophages function and regulating the basic components of immunity. ${ }^{33}$ Therefore, researchers indicated that elevated levels of APO A-I may predict better prognosis. 
Table 3 Univariate and Multivariate Analyses of OS in EBSCC Patients

\begin{tabular}{|c|c|c|c|c|}
\hline & \multirow{2}{*}{$\begin{array}{c}\text { Univariate Analyses } \\
\text { HR }(95 \% \mathrm{Cl})\end{array}$} & \multirow[t]{2}{*}{ P-value } & \multirow{2}{*}{$\begin{array}{c}\text { Multivariate Analyses } \\
\text { HR }(95 \% \mathrm{Cl})\end{array}$} & \multirow[t]{2}{*}{ P-value } \\
\hline & & & & \\
\hline Age (years) & & 0.102 & & \\
\hline$\leq 60$ & 1.000 & & & \\
\hline$>60$ & $0.543(0.26 \mathrm{I}-\mathrm{I} .128)$ & & & \\
\hline Gender & & 0.521 & & \\
\hline Female & 1.000 & & & \\
\hline Male & $1.375(0.520-3.634)$ & & & \\
\hline Tumor length $(\mathrm{cm})$ & & 0.028 & & \\
\hline$\leq 3.0$ & 1.000 & & & \\
\hline$>3.0$ & $2.954(1.126-7.748)$ & & & \\
\hline Tumor location & & 0.350 & & \\
\hline Upper/Middle & 1.000 & & & \\
\hline Lower & $0.679(0.302-1.528)$ & & & \\
\hline Vessel invasion & & 0.123 & & \\
\hline Negative & 1.000 & & & \\
\hline Positive & $1.804(0.853-3.814)$ & & & \\
\hline Smoking history & & 0.240 & & \\
\hline No & 1.000 & & & \\
\hline Yes & $1.579(0.737-3.387)$ & & & \\
\hline Drinking history & & 0.078 & & \\
\hline No & 1.000 & & & \\
\hline Yes & $2.033(0.924-4.475)$ & & & \\
\hline TNM stage & & 0.010 & & 0.002 \\
\hline 1 & 1.000 & & 1.000 & \\
\hline II-III & $2.811(1.277-6.185)$ & & 3.678 (1.609-8.407) & \\
\hline Surgery treatment & & 0.115 & & \\
\hline McKeown & 1.000 & & & \\
\hline Ivor Lewis & $0.558(0.270-1.152)$ & & & \\
\hline Adjuvant treatment & & 0.352 & & \\
\hline No & 1.000 & & & \\
\hline Yes & $1.424(0.677-2.995)$ & & & \\
\hline $\mathrm{TC}(\mathrm{mmol} / \mathrm{L})$ & & 0.857 & & \\
\hline$\leq 4.400$ & 1.000 & & & \\
\hline$>4.400$ & $1.072(0.500-2.298)$ & & & \\
\hline TG (mmol/L) & & 0.033 & & 0.006 \\
\hline$\leq 1.325$ & 1.000 & & 1.000 & \\
\hline$>1.325$ & $2.211(1.066-4.586)$ & & $2.906(1.356-6.229)$ & \\
\hline $\mathrm{HDL}-\mathrm{C}(\mathrm{mmol} / \mathrm{L})$ & & 0.109 & & \\
\hline$\leq 1.220$ & 1.000 & & & \\
\hline$>1.220$ & $0.543(0.257-1.145)$ & & & \\
\hline LDL-C (mmol/L) & & 0.918 & & \\
\hline$\leq 3.305$ & 1.000 & & & \\
\hline$>3.305$ & $1.042(0.475-2.283)$ & & & \\
\hline
\end{tabular}

(Continued) 
Table 3 (Continued).

\begin{tabular}{|c|c|c|c|c|}
\hline & Univariate Analyses & \multirow[t]{2}{*}{ P-value } & Multivariate Analyses & \multirow[t]{2}{*}{ P-value } \\
\hline & HR $(95 \% \mathrm{CI})$ & & HR $(95 \% \mathrm{CI})$ & \\
\hline APO A-I $(g / L)$ & & 0.014 & & 0.014 \\
\hline$\leq 1.305$ & 1.000 & & 1.000 & \\
\hline$>1.305$ & $0.359(0.158-0.814)$ & & $0.352(0.154-0.808)$ & \\
\hline APO B $(g / L)$ & & 0.536 & & \\
\hline$\leq 1.010$ & 1.000 & & & \\
\hline$>1.010$ & $0.786(0.367-1.685)$ & & & \\
\hline BMI $\left(\mathrm{kg} / \mathrm{m}^{2}\right)$ & & 0.978 & & \\
\hline$\leq 22.5$ & 1.000 & & & \\
\hline$>22.5$ & $1.010(0.490-2.085)$ & & & \\
\hline
\end{tabular}

Note: P-values $<0.05$ were shown in bold.

Abbreviations: EBSCC, esophageal basaloid squamous cell carcinoma; TC, total cholesterol; TG, triglyceride; Apo A-I, apolipoprotein A-I; Apo B, apolipoprotein B; HDLC, high-density lipoprotein-cholesterol; LDL-C, low-density lipoprotein-cholesterol; TNM, tumor, node, metastasis; CI, confidence interval; HR, hazard ratio; RFS, recurrence-free survival.

As we know, serum APO A-I, as an indicator of biochemical examination, is routinely tested in daily clinical practice, which makes it easily available. In this retrospective study, we have firstly found that patients with lower levels of preoperative serum APO A-I were associated with worse RFS and OS. Therefore, using APO A-I as a prognostic biomarker for OS and/or RFS in EBSCC patients is convenient and acceptable. Moreover, clinicians can predict survival and improve treatment outcomes according to the levels of serum APO A-I. In the current study, according to the ROC/AUC analysis, the optimal cut-off value for serum APO A-I in EBSCC was $1.305 \mathrm{~g} / \mathrm{L}$. According to this threshold, if a patient's serum APO A-I less than $1.305 \mathrm{~g} / \mathrm{L}$, it is recommended to improve the serum APO A-I status before radical resection, or to apply adjuvant therapy after surgery.

Serum levels of APO A-I in cancer patients including ESCC patients were significantly lower than those in normal controls. Wang et $\mathrm{al}^{17}$ revealed that the mean values of APO A-I in ESCC were significantly lower than health controls $(1.21 \mathrm{~g} / \mathrm{L}$ vs $1.56 \mathrm{~g} / \mathrm{L}, \mathrm{P}<0.001)$. In the current study, the mean value of APO A-I in EBSCC was $1.26 \pm 0.24 \mathrm{~g} / \mathrm{L}$. Serum APOA-I as well as lipids and cholesterol levels may be affected by many factors including dietary and alcohol habits. In the current study, serum APO A-I was significantly associated with drinking history $(P=0.033)$. However, no differences were found about the levels of APO A-I grouped by drinking history $(1.32 \pm 0.22 \mathrm{~g} / \mathrm{L}$ vs $1.23 \pm 0.24 \mathrm{~g} / \mathrm{L}$, $P=0.571)$. Recent studies revealed that higher alcohol consumption was the main determinants of APO A-I levels. ${ }^{34}$ However, the results were opposite in the current study and another study reported by Ye et $\mathrm{al}^{35}$ in colorectal cancer. The results indicated that patients with no drinking history had the higher levels of APO A-I than those with drinking history $(1.08 \mathrm{~g} / \mathrm{L}$ vs $1.01 \mathrm{~g} / \mathrm{L}$, $P=0.017)$. We analyzed the possible reasons. Firstly, there may be some bias due to the small sample size. Secondly, the drinking history in the current study was defined as a history of drinking in the past, whether or not the patient was currently abstained. Therefore, the levels of APO A-I may be back to the starting level of abstention. ${ }^{36}$ It should be noted that serum lipid concentrations may be strongly associated with dietary habits. However, all the patients in the current study were from the same province and the same Han nationality, their dietary habits were similar. Although published study reported that serum APO A-I levels did not differ between the different diet groups, ${ }^{37}$ the results also should be regarding with caution.

Some potential limitations should be acknowledged. Firstly, this is a retrospective study in a single-center. Secondly, the sample size is small. Therefore, the statistical efficiency is greatly reduced, which may affect the stability of the results. However, given that EBSCC is such a rare disease, only a small number of cases could be collected from a single-center. Therefore, the current study also added something novel to the literature. Thirdly, serum APO-AI as well as lipids and cholesterol levels in plasma are affected by many factors including dietary habits. Although previous 


Points
Tumor.length
APOAI
TNM
Linear Predictor
1-year Survival Probability
3-year Survival Probability
5-year Survival Probability

Points

TG

APOAI

TNM

Total Points

Linear Predictor

1-year Survival Probability

3-year Survival Probability

5-year Survival Probability
A

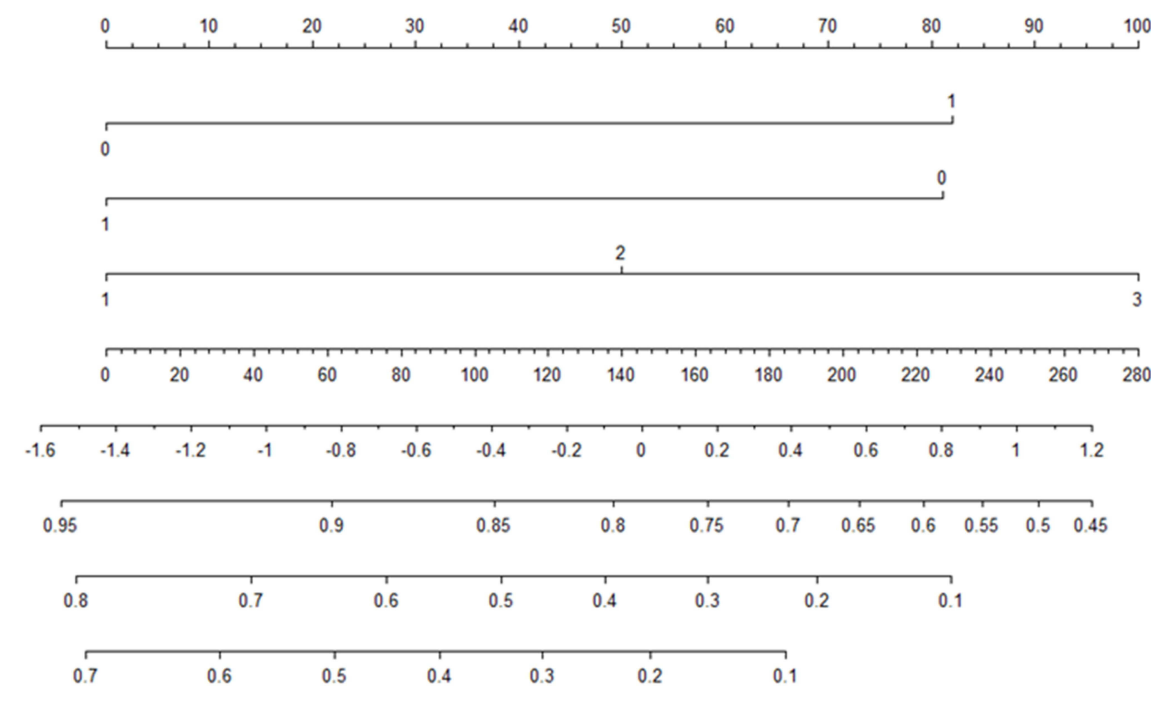

B
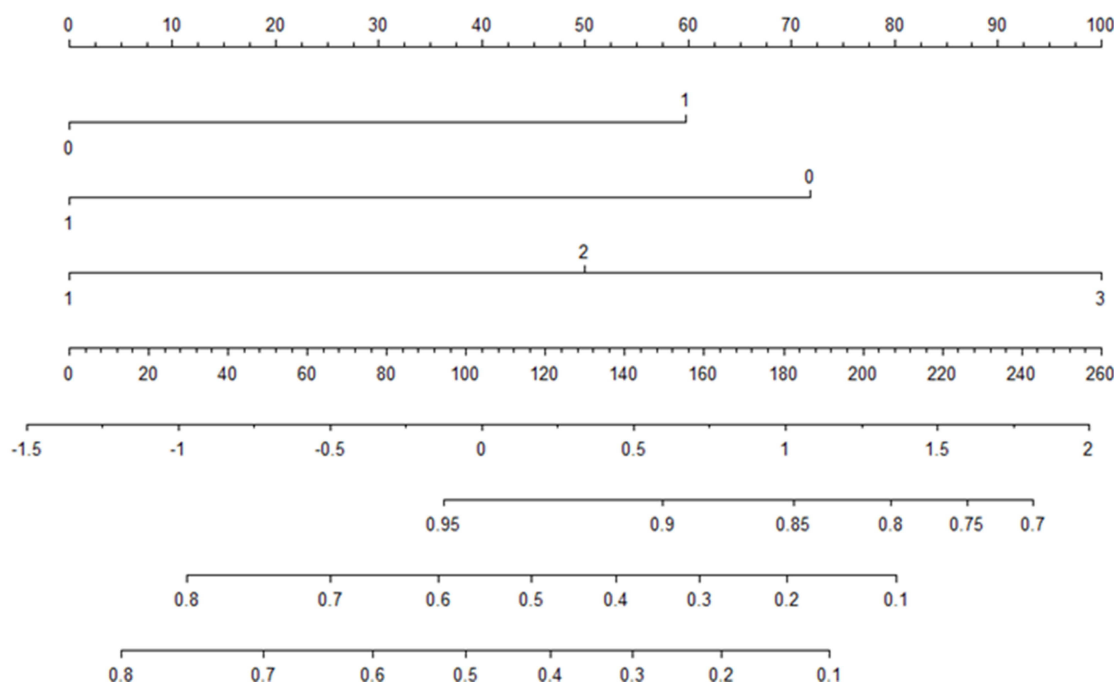

Figure 5 Nomogram analyses. Nomograms based on APO A-I for predicting the 1-, 3- and 5-year RFS (A) and OS (B).

study reported that serum APO A-I levels did not differ between the different diet groups, ${ }^{37}$ the results also should be regarding with caution. Fourthly, this study spanned a large period (from 2007 to 2018). The levels of APO A-I and other lipids and cholesterol levels may be different during the different periods. Therefore, the results also should be regarding with caution. Fifthly, although two recent meta-analyses reported no obvious difference in the surgical outcomes between McKeown and Ivor Lewis, ${ }^{38,39}$ it should be noted that the different surgical approaches may provide obvious interference to the results. Finally, two nomogram models based on APO A-I and other prognostic factors in the current study were conducted to predict the 1-,
3- and 5-year RFS and/or OS probability for patients with EBSCC. However, we must acknowledge that our prognostic nomogram models were only developed due to a limited sample size, but not validated in large samples for external or internal case verification. Therefore, the credibility and persuasiveness of the results are further reduced. The prognostic results of preoperative serum APO A-I should be validated in future.

In conclusion, serum APO A-I serves as a useful potential predictor in EBSCC patients. As far as we know, this is the first study to identify and investigate the prognostic role of preoperative serum APO A-I in patients with EBSCC. 

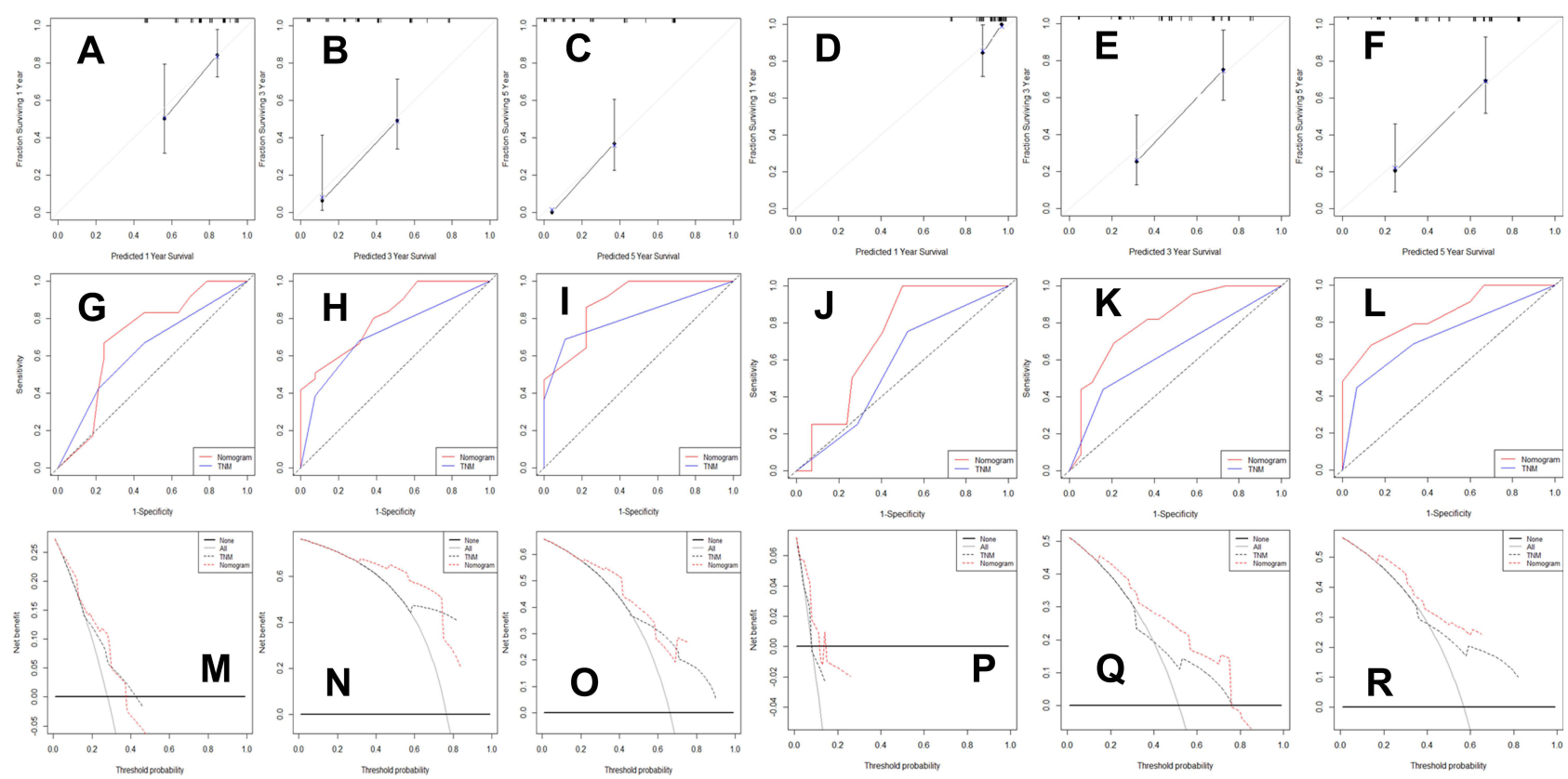

Figure 6 Nomogram established regarding RFS and OS prediction. The calibration curve presented an acceptable agreement for RFS (A-C) and OS (D-F). Timedependent ROC curve analyses revealed that the nomogram $(0.70,0.8 \mathrm{I}$ and 0.88 for I-, 3- and 5-year RFS prediction [G-I] and $0.72,0.8 \mathrm{I}$ and 0.84 for I-, 3- and 5-year OS prediction [J-L) was significantly higher than traditional TNM staging systems ( $0.63,0.7 \mathrm{I}$ and 0.82 for I-, 3- and 5-year RFS prediction and $0.57,0.64$ and 0.73 for I-, 3- and 5 -year OS prediction). The APO A-I-based nomogram model had higher overall net benefits than traditional TNM staging systems according to the decision curve analyses in RFS (M-O) and OS (P-R).

\section{Acknowledgment}

The authors would like to acknowledge Dr. Wen-Juan Yin for providing pathological results.

\section{Funding}

This study was funded by the Medical Health Science and Technology Project of Zhejiang Provincial Health Commission (2018KY290, 2019RC129 and 2019RC128). This study was also supported by Zhejiang TCM Science and Technology Project (2021ZB034).

\section{Disclosure}

The authors declare that they have no conflicts of interest for this work.

\section{References}

1. Wain SL, Kier R, Vollmer RT, et al. Basaloid-squamous carcinoma of the tongue, hypopharynx, and larynx: report of 10 cases. Hum Pathol. 1986;17(11):1158-1166. doi:10.1016/S0046-8177(86)80422-1

2. Lam KY, Law S, Luk JM, et al. Oesophageal basaloid squamous cell carcinoma: a unique clinicopathological entity with telomerase activity as a prognostic indicator. $J$ Pathol. 2001;195(4):435-442. doi:10.1002/ path. 984

3. Zhang BH, Cheng GY, Xue Q, et al. Clinical outcomes of basaloid squamous cell carcinoma of the esophagus: a retrospective analysis of 142 cases. Asian Pac J Cancer Prev. 2013;14(3):1889-1894. doi:10.7314/APJCP.2013.14.3.1889
4. Xiao Q, Zhang B, Deng X, et al. The preoperative neutrophil-tolymphocyte ratio is a novel immune parameter for the prognosis of esophageal basaloid squamous cell carcinoma. PLoS One. 2016;11 (12):e0168299. doi:10.1371/journal.pone.0168299

5. Sato-Kuwabara Y, Fregnani JH, Jampietro J, et al. Comparative analysis of basaloid and conventional squamous cell carcinomas of the esophagus: prognostic relevance of clinicopathological features and protein expression. Tumour Biol. 2016;37(5):6691-6699. doi:10.1007/s13277-015-4551-3

6. Saito T, Mitomi H, Yao T. Molecular pathology and potential therapeutic targets in esophageal basaloid squamous cell carcinoma. Int J Clin Exp Pathol. 2015;8:2267-2273.

7. Chang SJ, Hou MF, Tsai SM, et al. The association between lipid profiles and breast cancer among Taiwanese women. Clin Chem Lab Med. 2007;45(9):1219-1223. doi:10.1515/CCLM.2007.263

8. Zhang X, Zhao XW, Liu DB, et al. Lipid levels in serum and cancerous tissues of colorectal cancer patients. World J Gastroenterol. 2014;20 (26):8646-8652. doi:10.3748/wjg.v20.i26.8646

9. Chetty PS, Mayne L, Lund-Katz S, et al. Helical structure and stability in human apolipoprotein A-I by hydrogen exchange and mass spectrometry. Proc Natl Acad Sci USA. 2009;106 (45):19005-19010. doi:10.1073/pnas.0909708106

10. Zamanian-Daryoush M, Lindner D, Tallant TC, et al. The cardioprotective protein apolipoprotein $\mathrm{A} 1$ promotes potent antitumorigenic effects. $J$ Biol Chem. 2013;288(29):21237-21252. doi:10.1074/jbc.M113.468967

11. Fuhrman B, Gantman A, Aviram M. Paraoxonase 1 (PON1) deficiency in mice is associated with reduced expression of macrophage SR-BI and consequently the loss of HDL cytoprotection against apoptosis. Atherosclerosis. 2010;211(1):61-68. doi:10.1016/ j.atherosclerosis.2010.01.025

12. Bhattacharyya T, Nicholls SJ, Topol EJ, et al. Relationship of paraoxonase 1 (PON1) gene polymorphisms and functional activity with systemic oxidative stress and cardiovascular risk. JAMA. 2008;299 (11):1265-1276. doi:10.1001/jama.299.11.1265 
13. Ma M, Yuan SQ, Chen YM, et al. Preoperative apolipoprotein B/ apolipoprotein A1 ratio: a novel prognostic factor for gastric cancer. Onco Targets Ther. 2018;11:2169-2176. doi:10.2147/OTT.S156690

14. Mao M, Wang X, Sheng H, et al. A novel score based on serum apolipoprotein A-1 and C-reactive protein is a prognostic biomarker in hepatocellular carcinoma patients. BMC Cancer. 2018;18(1):1178. doi:10.1186/s12885-018-5028-8

15. Jiang R, Yang ZH, Luo DH, et al. Elevated apolipoprotein A-I levels are associated with favorable prognosis in metastatic nasopharyngeal carcinoma. Med Oncol. 2014;31(8):80. doi:10.1007/s12032-0140080-y

16. Wu J, Zhang C, Zhang G, et al. Association between pretreatment serum apolipoprotein A1 and prognosis of solid tumors in Chinese population: a systematic review and meta-Analysis. Cell Physiol Biochem. 2018;51(2):575-588. doi:10.1159/000495277

17. Wang XP, Li XH, Zhang L, et al. High level of serum apolipoprotein A-I is a favorable prognostic factor for overall survival in esophageal squamous cell carcinoma. BMC Cancer. 2016;16(1):516. doi:10.11 86/s12885-016-2502-Z

18. Zhang Y, Yang X. Prognostic significance of pretreatment apolipoprotein A-I as a noninvasive biomarker in cancer survivors: a meta-analysis. Dis Markers. 2018;2018:1034037. doi:10.1155/2018/ 1034037

19. Yang YS, Shang QX, Yuan Y, et al. Comparison of long-term quality of life in patients with esophageal cancer after Ivor-Lewis, Mckeown, or Sweet esophagectomy. J Gastrointest Surg. 2019;23(2):225-231. doi:10.1007/s11605-018-3999-z

20. Helminen O, Mrena J, Sihvo E. Can we increase the resection rate by minimally invasive approach? Experience from 100 minimally invasive esophagectomies. J Oncol. 2019;2019:3809383. doi:10.1155/ 2019/3809383

21. Rice TW, Ishwaran H, Hofstetter WL, et al. Recommendations for pathologic staging (pTNM) of cancer of the esophagus and esophagogastric junction for the 8th edition AJCC/UICC staging manuals. Dis Esophagus. 2016;29(8):897-905. doi:10.1111/dote.12533

22. Iasonos A, Schrag D, Raj GV, et al. How to build and interpret a nomogram for cancer prognosis. J Clin Oncol. 2008;26(8): 1364-1370. doi:10.1200/JCO.2007.12.9791

23. Salami A, Abbas AE, Petrov R, et al. Comparative analysis of clinical, treatment, and survival characteristics of basaloid and squamous cell carcinoma of the esophagus. J Am Coll Surg. 2018;226 (6):1086-1092. doi:10.1016/j.jamcollsurg.2017.10.019

24. Cho KJ, Jang JJ, Lee SS, et al. Basaloid squamous carcinoma of the oesophagus: a distinct neoplasm with multipotential differentiation. Histopathology. 2000;36(4):331-340. doi:10.1046/j.1365-2559.2000. 00851.x

25. Klaase JM, Hulscher JB, Offerhaus GJ, et al. Surgery for unusual histopathologic variants of esophageal neoplasms: a report of 23 cases with emphasis on histopathologic characteristics. Ann Surg Oncol. 2003;10(3):261-267. doi:10.1245/ASO.2003.05.029

26. Chen SB, Weng HR, Wang G, et al. Basaloid squamous cell carcinoma of the esophagus. J Cancer Res Clin Oncol. 2012;138 (7):1165-1171. doi:10.1007/s00432-012-1180-8
27. Imamhasan A, Mitomi H, Saito T, et al. Immunohistochemical and oncogenetic analyses of the esophageal basaloid squamous cell carcinoma in comparison with conventional squamous cell carcinomas. Hum Pathol. 2012;43(11):2012-2023. doi:10.1016/j.humpath.20 12.02 .010

28. Georgila K, Vyrla D, Drakos E. Apolipoprotein A-I (ApoA-I), immunity, inflammation and cancer. Cancers (Basel). 2019;11(8):1097. doi:10.3390/cancers 11081097

29. Welti J, Loges S, Dimmeler S, et al. Recent molecular discoveries in angiogenesis and antiangiogenic therapies in cancer. J Clin Invest. 2013;123(8):3190-3200. doi:10.1172/JCI70212

30. Gao F, Vasquez SX, Su F, et al. L-5F, an apolipoprotein A-I mimetic, inhibits tumor angiogenesis by suppressing VEGF/basic FGF signaling pathways. Integr Biol (Camb). 2011;3(4):479-489. doi:10.1039/ $\mathrm{c} 0 \mathrm{ib} 00147 \mathrm{c}$

31. Su F, Kozak KR, Imaizumi S, et al. Apolipoprotein A-I (apoA-I) and apoA-I mimetic peptides inhibit tumor development in a mouse model of ovarian cancer. Proc Natl Acad Sci USA. 2010;107 (46):19997-20002. doi:10.1073/pnas.1009010107

32. Kobayashi Y, Kashima H, Wu RC, et al. Mevalonate pathway antagonist suppresses formation of serous tubal intraepithelial carcinoma and ovarian carcinoma in mouse models. Clin Cancer Res. 2015;21 (20):4652-4662. doi:10.1158/1078-0432.CCR-14-3368

33. Tietge UJ, Maugeais C, Cain W, et al. Overexpression of secretory phospholipase $\mathrm{A}(2)$ causes rapid catabolism and altered tissue uptake of high density lipoprotein cholesteryl ester and apolipoprotein A-I. J Biol Chem. 2000;275(14):10077-10084. doi:10.1074/jbc.275.14.10077

34. Frondelius K, Borg M, Ericson U, et al. Lifestyle and dietary determinants of serum apolipoprotein A1 and apolipoprotein B concentrations: cross-sectional analyses within a Swedish cohort of 24,984 individuals. Nutrients. 2017;9(3):211. doi:10.3390/nu9030211

35. Ye J, Luo QY, Wang XP, et al. Serum apolipoprotein A-I combined with C-reactive protein serves as a novel prognostic stratification system for colorectal cancer. Cancer Manag Res. 2019;11: 9265-9276. doi:10.2147/CMAR.S215599

36. Välimäki M, Laitinen $\mathrm{K}$, Ylikahri R, et al. The effect of moderate alcohol intake on serum apolipoprotein A-I-containing lipoproteins and lipoprotein (a). Metabolism. 1991;40(11):1168-1172. doi:10.10 16/0026-0495(91)90211-E

37. Bradbury KE, Crowe FL, Appleby PN, et al. Serum concentrations of cholesterol, apolipoprotein A-I and apolipoprotein B in a total of 1694 meat-eaters, fish-eaters, vegetarians and vegans. Eur J Clin Nutr. 2014;68(2):178-183. doi:10.1038/ejen.2013.248

38. van Workum F, Berkelmans GH, Klarenbeek BR, et al. McKeown or Ivor Lewis totally minimally invasive esophagectomy for cancer of the esophagus and gastroesophageal junction: systematic review and meta-analysis. J Thorac Dis. 2017;9(S8):S826-S833. doi:10.21037/ jtd.2017.03.173

39. Deng J, Su Q, Ren Z, et al. Comparison of short-term outcomes between minimally invasive McKeown and Ivor Lewis esophagectomy for esophageal or junctional cancer: a systematic review and meta-analysis. Onco Targets Ther. 2018;11:6057-6069. doi:10.2147/OTT.S169488
Cancer Management and Research

\section{Publish your work in this journal}

Cancer Management and Research is an international, peer-reviewed open access journal focusing on cancer research and the optimal use of preventative and integrated treatment interventions to achieve improved outcomes, enhanced survival and quality of life for the cancer patient.
The manuscript management system is completely online and includes a very quick and fair peer-review system, which is all easy to use. Visit http://www.dovepress.com/testimonials.php to read real quotes from published authors. 